The New Review of Academic Librarianship, 1, 1995, 57-84

\title{
Management information systems in some academic libraries in Britain
}

Dudung Gumilar

Central Library, Institut Keguram dam I Imu Pendidikan, (Institute of Teacher

Training and Education), Bandung, Indonesia

and

Ian M. Johnson

School of Librarianship and Information Studies, The Robert Gordon

University, Aberdeen

\begin{abstract}
This paper examines the potential and actual use of computer generated information in decision making by academic library managers.

It begins by discussing some of the contemporary issues in British higher education which are compelling library managers towards establishing a more formal planning process and towards making more systematic use of information in their decision making, especially in resources allocation and service evaluation. It considers the general features of Management Information Systems, particularly automated systems, and reviews the general development of automated library systems in British academic libraries.
\end{abstract}

It then examines the current state of development of Management Information Systems in some British academic libraries. To illustrate developments, a survey of eight academic libraries in England and Scotland was undertaken in late 1991. The results of the survey showed that automated Management Information Systems are not widely available to library managers. Only two of the eight libraries made much use of their library automation systems for management information.

Problems to be overcome include the crude form of data provided by existing automated library systems, a lack of agreement on what data is required for management purposes, and a lack of expertise on the part of library staff in interpreting data. The cost of establishing Management Information Systems and the absence of Management Information systems in the parent institutions had also inhibited their widespread adoption by academic libraries. However, it appears that the introduction of Management Information systems poses no threats to library staff, because most libraries already have a 'flat' management structure. The preferred option of most of the librarians is to await the future development of the more advanced Decision Support Systems, but the implementation of such systems may encounter similar obstacles.

\section{I ntroduction}

Without proper information, library managers will always face some difficulty in decision making. The application of management information, in particular that derived from automated systems, has a potentially important role in relation to current problems faced by libraries. Management information has been available 
to librarians for a long time, based on manually compiled records, but libraries have not always had access to computer generated information.

Consequently, the potential of Management Information Systems has lain hidden. By the late 1980s, however, most academic libraries in the United Kingdom had computerised the main library operations. The first part of this paper considers the growing importance of a formal planning process in library management. Next it discusses the relationship of the library planning process and Management Information Systems, and describes how computer systems can be used as a tool to produce management information. It then goes on to review the development of automated library systems.

The final part of the paper reports on a small survey, conducted in late 1991, of selected academic libraries in Britain: four university libraries, three Polytechnics, and one Scottish Central Institution. This survey investigated:

- the use of information in decision making

- whether libraries' automated systems are currently being used as Management Information Systems

- the barriers within organisations that hinder the implementation of Management Information Systems

- $\quad$ perceptions of the future of Management Information Systems in academic libraries.

\section{Academic libraries and their management}

The higher education sector in Britain comprises universities established over the last seven hundred years, including a number designated during the last phase of expansion in the mid-1960s, and those institutions which were mostly redesignated as universities in 1992 - the Polytechnics and their Scottish equivalents, the Central Institutions, as well as certain Colleges of Higher Education.

The expansionary momentum of the 1960s and 1970s was followed by pressure for efficiency and economies. The 1980s was not a period in which academic libraries prospered. The political and economic situation became difficult for all higher education institutions.

'The University of Sussex, for instance, and its funding reduced by 20 per cent between 1981 and 1984, and is now facing a further reduction by $1990 .{ }^{1}$

This was usually followed by a reduction in financial support for their libraries. Nonetheless, some found this environment a beneficial challenge. Mackenzie observed that:

'it may be that a measure of austerity is beneficial in that it encourages creative thought and more effective management.' 2

In particular, academic library managers needed to use a more formal planning process to focus their services on meeting users' needs. Sparrow illustrated the planning process as:

- Establishing overall objectives

- Allocating library resources to programmes

- Evaluating attainment of objectives. ${ }^{3}$

McClure provides a detailed rationale for the planning process: 
'In the times of economic difficulties for many academic libraries, the need for a planning process takes on significant importance in six general areas.

First, planning provides for a rational response to uncertainty and change.

Although the organisation cannot control its environment, it may be able to manipulate it - assuming there is an objective to be accomplished.

Second, planning focuses attention on goals and objectives. Does your organisation have a written set of goals and objectives? If not, dysfunctions, departmental competition, and ineffective resource allocation are likely. Third, planning is important as an aid to resource allocation by establishing priorities for funding. Which services can be provided at the least cost and for the most benefit?

Fourth, planning also serves as a basis for determining individual, departmental, organisational, or program accountability.

Fifth, planning facilitates control of organisational operations by collecting information to evaluate the various programs or services.

Finally, planning orients the organisation to a futuristic stance. Instead of always reacting to problem situations, the organisation attempts to foresee and mitigate against future problems before they become crises. ${ }^{4}$

Sparrow also emphasised that:

'Precise and consistent objectives provide guidance and direction for managers to develop plans ... for allocating resources in line with objectives and ... for monitoring and controlling these resources. ${ }^{5}$

At the institutional level, all academic library managers must negotiate the library's resource requirements through various supervisory committees. To support their claims, academic librarians clearly need information which can be presented to these committees about how effectively the libraries contribute to the objectives of the parent institutions. For example,

'Libraries are required now to develop services which can be targeted at different groups based on their own needs. The changing demography of higher education argues for a careful and continuing monitoring of such factors as the profile of the student population, measurement of library use by identified subgroups and experimentation with new services and assessment of their impact.' 6

The latest approach to higher education funding in Britain places more emphasis on requiring institutions to show how effectively their money was spent. The concept of 'cost centres' was introduced by the government's Department of Education and Science (DES) through its semi-autonomous funding agencies for higher education, the Universities Funding Council (UFC) and the Polytechnic and Colleges Funding Council (PCFC). A cost centre is:

'a location or items or equipment in respect of which cost may be ascertained and related to cost units for control purposes.' 7

Subsequently, the DES encouraged higher education institutions in England and Wales to make use of performance indicators, and as a follow up, in 1990, the DES surveyed the use of performance indicators. The survey showed that, in the PCFC institutions, 43 had used performance indicators, including indicators of performance in their libraries. The two most common performance indicators applied to libraries were: Seats per-full-time equivalent (FTE) student; and number of loans per reader. ${ }^{8}$ 


\section{Organisational structures and information flows}

An organisational structure is a means to incorporate various functions in order to pursue some predetermined objectives. ${ }^{9}$ Organisational structures also provide the lines along which information flows.

Stueart and Eastlick ${ }^{10}$ have described two ways to organise libraries. They are 1) specialisation; and 2) coordination and integration. Coordination and integration simply means bringing together all individual efforts to achieve particular objectives. Specialisation, however, can be interpreted in two approaches: departmentalisation and hierarchy.

Departmentalisation means the organisation is structured horizontally by identifying and grouping similar or related required activities or tasks into departments, for example, function, activities, geography, subjects, form of material, etc. There are two main approaches to departmentalisation within academic libraries, function and subject, and they are matters of continual debate. The first approach is a structure dominated by administrative function. The subject divisional library is the alternative approach to the strictly functional. The staff are split by subject, with services and processing entirely subordinate. Hunt has, however, observed that:

'The introduction of computers into academic libraries is a major reason why the debate between functionalism and subject organisation has been bypassed. ${ }^{11}$

This is perhaps because one consequence of automation has been that: 'Technology has reduced the time necessary to carry out one of the most tedious part's of librarian's work, record creation and manipulation.' ${ }^{12}$

The second method of specialisation in organisations is the creation of a vertical hierarchy, with the individuals located on the top of organisation having more authority than those at successively lower levels.

'Such structures are often also represented diagrammatically as a family-tree, depicting line management responsibilities above and below. And any given structure can be either functional (that is, organised into separate departments, each concerned with single library process or activity) or subject-orientated (in which the professional staff are individually responsible for a range of library processes and activities in a given subject area).' ${ }^{13}$

The merits of a hierarchical structure have been questioned by Line; he points out several problems, such as:

'reporting lines tends to be long, and the responsibility of any individual very limited. Many staff rarely come into contact with staff more than one or two grades higher, with the result that communication is often poor and it is hard for staff below a senior level to have any sense of involvement in the organisation.' ${ }^{14}$

In place of a hierarchical structure, Line proposed a 'flat' structure as one possibility for libraries in the near future. In examining the rapid change and different climate that are being encountered by libraries, Cargill described the 'flat' management structure as having:

'fewer middle managers, and more reliance on the two extremes - the senior administrators and lower level staff - to make decisions.' ${ }^{15}$ 
It could be speculated that the implications for the development of Management Information Systems (MIS) in libraries with 'flat' management structures may be comparable to the general problems of introducing MIS in small organisations:

'Larger organisations have found greater success with MIS use than smaller ones. Libraries, even the largest, are relatively small organisations and much planning is required to initiate and gain acceptance of MIS. There will be more resistance in small organisations than in very large ones since the likelihood of a lesser degree of bureaucratisation and traditional line and staff authority divisions are in place in such operations. The perception of the MIS as crystallising these divisions may offset their initial acceptance.' ${ }^{16}$

\section{Decision making, organisational structures, and information needs}

Whether organisations are large or small (or 'flat'), there is managerial stratification. The tasks of top management are development of the organisation's domain, management of the interface with external environments and establishment of the organisation's administrative climate; middle management develop rules, procedures and policies for day-to-day operations; and technical management sees that services are rendered and policies carried out. ${ }^{17}$

In a conference on Management Information Systems, Brophy identified the library staff with each of these management levels as follows:

- senior/top managers (e.g. deputies and chiefs).

- middle managers (e.g. heads of major divisions)

- line/technical managers (e.g. service desk superintendents).

He also commented that

'some individuals will straddle more than one category. Deputies, for example, will be concerned with middle management (in terms of day to day operations) and senior management (in terms of strategic planning). Furthermore the model is generalised, and it is true that in smaller libraries such stratification may break down since everyone is doing a bit of everything!' 18

Decision making has been defined by Radford as:

'the formulation of alternative courses of action to meet the situation under consideration and in the choice between these alternatives after an evaluation of the effectiveness in achieving the decision maker's objectives. One of the most important factors is information from which an appreciation of the decision can be made.' 19

According to Ahituv and Neumann, there are three stages in decision making: 1) intelligence; 2) design, and 3 ) choice. ${ }^{20}$ The intelligence stage encompasses collection, classification, processing, and presentation of the data necessary for the later stages of the decision making process. During the design stage, the decision maker outlines alternative solutions, each of which involves a set of actions to be taken. He usually uses quantitative techniques and design tools such as are common in management sciences and system analysis. The data gathered in the previous stage is now examined in statistical and other models to forecast possible outcomes for each alternative. In the choice stage, the decision maker is faced with various alternatives. One alternative must be selected, which becomes the formal decision and consequently generates actions to be 
taken. This may seem deceptively easy, but in reality there are many difficulties that usually make choice a complex stage.

It becomes clear that decision making is the conversion of information into action. The intended actions are planning, organising, directing and controlling of activities to achieve objectives. However, decision making at different managerial levels is not necessarily an identical process, and there are clear implications for the type of management information required.

"The degree of structure is dependent on the degree of predictability of the variables involved in a given decision. Unstructured decisions have few predictable variables; structured ones have many. ... Unstructured decisions are usually made at the strategic planning level and semi-structured decisions at the operational management level. The most structured decisions are reached at the operational control level.' 21

Library managers might, therefore, be supposed to need access to the information which is appropriate to their level of decision making. Brindley has described the relationship between the needs for information in all three levels of library management:

"These levels and their various concerns obviously overlap, and in some cases may be undertaken by the same person, especially in smaller libraries. Nevertheless, the distinction remains a generally valid one, in terms of information need. At operational and some middle levels, formal information, systematically provided in short time comparisons, forms the bulk of what is required. Higher up the pyramid, unstructured information, much of it external, is a more significant consideration; also the more senior librarians will only want snapshot or selective sets of data derived, for example, from operational systems and the university budget.' 22

She also noted that:

'there are two kinds of management information, the formal and the informal. Both of them derived from external and internal sources to the academic library but informal management information are mostly found externally such as from the users and the administrators who govern budgets. ${ }^{23}$

\section{I nformation needs and performance measurement}

Information which is reliable, accurate, timely and well presented will always help library managers to make decisions. Moreover:

'Systematic procedures are needed for allocating resources in line with objectives and ways must be found for monitoring and controlling these resources.' 24

Performance assessment is the systematic measurement of the extent to which a library has achieved its objectives in a certain period of time. ${ }^{25}$ Performance assessment can be applied in libraries, in the contemporary British terminology, to: service input cost measures, service output measures, service effectiveness measures, and service domain measures. ${ }^{26}$ Internally, performance assessment is concerned with making the library work efficiently and effectively. Externally, it can be used by library managers to justify the budget to the parent body.

Without performance assessment it is difficult to determine how well the library is progressing. The term 'performance assessment' encompasses both performance indicator and performance measure. ${ }^{27}$ 
Performance indicators:

'provide objective data on the extensiveness and effectiveness of library services. They quantify library performance in terms of goals achieved and services delivered $\ldots$ but to guide resource allocation. ${ }^{28}$

Four types of performance indicators have been defined. ${ }^{29}$ They are operational performance indicators, effectiveness indicators, cost-effectiveness indicators and impact indicators. Redfern also observed that performance indicators are intended to improve decision making and service performance, aid public accountability and help define and evaluate policies. ${ }^{30}$ Winkworth commented that if performance indicators are seriously used and real consequences follow from the judgements based on them, then all concerned should be aware that the chosen performance indicators will come to be taken by the staff to be representative of the objectives of the library. ${ }^{31}$

The relationship between performance measures and performance indicators is that they:

'can not be interpreted in the same way. Though the indicators are calculated from direct measures, there are some important factors, such as higher order effects, the particular aims of the library, or certain attributes of what is being measured, which can not be brought into the calculation. Therefore, however carefully it is arrived at, a performance indicator can not be seen as an absolute measure of performance, but as guide which needs to be considered in relation to local conditions and other indicators.' ${ }^{32}$

\section{Management information systems}

Heim has defined a Management Information System as:

'the process and structure used by an organisation to identify, collect, evaluate, transfer, and utilise information in order to fulfil its objectives. It is a system that provides management with information to make decisions, evaluate alternatives, measure performance, and detect situations requiring corrective action'. ${ }^{33}$

The implementation of performance assessment in academic libraries, according to Lines, ${ }^{34}$ is an essential part of good management practice. Although she had reservations about the current Management Information Systems in university libraries because, for example, few academic libraries had produced a statement of their objectives, she still believed that Management Information Systems could contribute to effective management of library activities.

The four main objectives for Management Information systems have been defined as:

1. to facilitate the decision making process in the library by providing the managers with accurate, timely, and selective information that assists them in determining a specific course of action.

2. to provide for the objective performance measurement and assessment of selected relevant areas of the library. The areas are to be determined during strategic planning.

3. to provide pertinent information about the library's internal and external environments.

4. to provide information on alternative strategies and contingency plans. ${ }^{35}$ 
The purposes above can only be implemented if people look upon Management Information Systems as an integral part of the framework of management in the academic library and not as a peripheral system which has been installed for the benefit of an individual or a single department.

"There may be subsystems within the larger system, which may be branch libraries, or departmental divisions such as cataloguing, acquisitions or circulation, but they must still be seen as integrated parts of the whole, and must function as such ... In the systems approach, however, the library organisation must be seen as an organic whole, with information as its lifeblood and in which each part of the system is integrated by the flow of information throughout.' 36

An integrated Management Information System is very important because it can be used to provide supporting information to determine:

1. efficiency; is the library doing things right?

2. effectiveness: is the library doing the right things?

3. competitiveness: is the library heading in a direction which is consistent with the environment (that is, does the library have a strategy, and is it certain that it is the correct one) ? ${ }^{37}$

Any discussion of the Management Information System must lead to consideration of the inputs data, processing data and the outputs data. Inputs to the management information system consist of both internally and externally generated library data. External information covers factors such as legislation, politics, trends in society, changes in technology, user demand, and comparative statistics for other, similar institutions. Internal data is that derived from administrative routines and transactional information. Administrative routines include those related to personnel, finance, acquisition, cataloguing, processing of materials, binding, building services, maintenance services, etc. Output measures will include data of circulation, general user satisfaction, etc. All service points will need to be monitored so that internal performance comparisons can be made and the contribution of each service point are the overall objectives of the organisation assessed.

In term of library managers' needs, a variety of inputs is evidently needed. It may be necessary to process information in different ways for different levels of decision-making needs, and different types of output reports will be needed to meet those different needs. Selection of appropriate data elements for inclusion in a Management Information System assumes that:

1. clear goals and measurable objectives have been developed for the library,

2. for each data element there is rationale for how it will be used or in what combinations with other data elements it can be used to determine success toward the accomplishment of objectives, overall library effectiveness, or performance measures for specific library services/operations, and

3. the library can, in fact, collect reliable and valid data for a particular data element.' 38

The data in a management information system also needs to be processed to turn it into meaningful information for library management. For this reason, management information systems require an appropriate data processing system. Data processing, according to Hicks, ${ }^{39}$ is the capture, storage and processing of data for the purpose of transforming it into information useful for decision making. 
In recent years, data processing for management information systems in business and industry has increasingly been undertaken by computers. 'a modem MIS will always rely to some extent on computer technology, although a computer is not a requirement. The reality of the 1980's would indicate that a computer is a necessity for the most sophisticated systems.' ${ }^{40}$

In libraries, in contrast, the development of the use of computer has been: 'modular, in the sense that it is based on a single library operation such as acquisitions, serials, control or cataloguing. The more general applications of management information lay hidden, as it is often seen only as a departmental resource.' ${ }^{41}$

This need not necessarily have been so. An early prediction of the advantages of information produced by computers was made in 1979 by Tague, who suggested that computers should produce information for control at both macro and micro level in libraries. ${ }^{42}$ However, in 1986, Brophy, having analysed eight large computer systems used in British libraries, noted that:

'automated library systems seem to be primarily about control at the micro level.' ${ }^{43}$

Moreover, they produced management information which was

'relatively crude, highly structured and very much a system by-product.' ${ }^{44}$

The needs of individual managers tended to be overlooked, especially when the design of MIS was in the hands of computer personnel.

'Too often, management information has been produced as an afterthought following computerisation. Most computerised issue systems, for example, were never designed to produce management information although librarians have often struggled over the data generated by these systems in an attempt to derive some meaningful information about issue patterns.' ${ }^{45}$

Technological changes have helped to ease this problem. As opposed to the use of mainframe and mini-computers,

'the advent of the microcomputer now provides an alternative to the dependence on large-scale centralised computer systems. Computer power can now be deployed cheaply to different parts of an organisation to allow for local processing of data.' ${ }^{46}$

Computers should be easily able to provide four types of report: periodic reports, exception reports, on demand reports, and predictive reports. ${ }^{47}$ Periodic reports provide routine, statistical information in detailed or summarised form.

Exception reports highlight areas requiring managerial attention and would focus on those that have been overlooked. On demand reports provide a response to a particular nonstandard question. Predictive reports give forecasts and provide comparisons based on statistical manipulation of data.

The principal requirement of the outputs of academic library management information systems is that they should be of interest to:

1. the relevant committee - the members wish to know how the library service is performing and whether the institution, is getting value for money.

2. the chief financial officer - his role is primarily custodial, and he wants to be assured that there is no overspending and that money is used for the purpose intended. 
3. the chief librarian - who wants to know how services under his control are performing in accordance with plans, targets and budgets.

4. the managers of individual sections or services - who want to have data on the operations and performance with plans, targets and budgets.

5. outside organisations requesting library performance data on a regular basis (for example, the Funding Councils, or the Standing Conference of National and University Libraries - SCONUL) ${ }^{48}$

In these ways, the outputs of management information systems become information for decision making. In general, management information is: 'the right information in the right form at the right time, so enabling the manager effectively and efficiently to do his/her job.' ${ }^{49}$

The value or quality of management information is determined by three factors. They are:

\section{1. the content of information}

Information is the substance of communication, but to be information rather than data or noise, it must be meaningful, relevant and new to the receiver.

\section{2. the form or presentation of the information}

Information should be presented in a style and format readily understandable by the manager. This means that the producer of information must be aware of the recipient's knowledge of technical terms, numeracy/literacy levels, his individual characteristics, the characteristics of the group with which he works and so on. These and other factors help the information producer to form an idea of the perception level of the manager and increase the likelihood of producing understandable information capable of being used which, it will be recalled, is the only way information can create value.

\section{3. the timing of its presentation}

Information which is produced must be communicated to the manager in time to be used. Delays in data gathering, processing or communication can transform potentially vital information into worthless waste paper. ${ }^{50}$

In the planning process, information should support the decision making process. Since one of the major problems facing academic libraries is the impact of changes in available financial support, the Colleges of Further and Higher Education Group (CoFHE) of the Library Association has been considering the categories of management information required for making decisions concerning the budget. They concluded that these are:

1. information about the institutional identity of the library

2. information about the target group

3. information about the collection resources

4. information about the financial resources

5. information about library personnel

6. information about facilities and equipment

7. information about various programmes and functions.

CoFHE also considered the requirements for collecting management information, and suggested the following guidelines: 
1. The information sought must be worth the costs of collecting it - direct and indirect.

2. Consider sources of information already available within the institution before setting up mechanisms to collect it.

3. Keep the collection of information relevant, i.e. remember the purpose - 'to support the budget request.'

4. Remember to consider qualitative and quantitative data as both can be relevant. ${ }^{51}$

\section{Management information system vs. decision support system}

Adams identified five major problem areas of management information systems. They are:

1. Output is undiscriminating

2. The information is not analysed for a purpose

3. The data lacks integration

4. The system is not user-friendly

5. The information which is given by MIS may not be acceptable.

To overcome these problems, Adams and his colleagues at De Montfort University (formerly Leicester Polytechnic) have experimented with a decision support system.

'Decision support systems can be seen as an extension of the idea of management information systems to provide a wide range of information in a more flexible and interactive way. They are designed to support decision making needs of management rather than act a useful by-product of transaction processing systems.' ${ }^{52}$

The special feature of a decision support system is that it solves a major problem of management information systems, i.e. the poor communication between the system and the users, library managers. Decision support systems have interface outputs which are more live than those of management information systems. The main interfaces in decision support systems are:

1. Regular reports which provide information on parts of the system, which are predetermined by the system's users.

2. Event-centred reports in which a report is generated only when a predetermined event has occurred. This will usually be the result of an exceptional condition, which is signalled by the system.

3. Ad hoc reports which are generated in response to a stimulus by the system user to report on a condition which is not normally monitored.

4. A query language which enables the user to interface directly with the system and to test changes in conditions experimentally. This is usually performed with 'goal-seeking' and 'what if techniques.

Beside the interface output, a decision support system also provides the report formats which may be required by the system's user, ranging from simple oneoff designs to sophisticated presentations for senior managers. They are:

1. Standard reports containing details prompted by the system user but in a format determined by standard software.

2. Tailored reports containing information determined by the user and in a format designed by the user. 
3. Tabulations enabling the user to examine a range of statistical data rapidly, in either a standard or tailored format.

4. Spreadsheet format allowing the user to transfer data from the system into a separate format which can be manipulated in a statistical layout.

5. Graphic presentations providing a method of transmitting a trend analysis rapidly, and in a user-friendly manner.

Like management information systems, the data input into decision support systems can be external or internal data concerning the library. Adams has confirmed that three levels of influence on decision making can be isolated:

1. Information from the library's operations

2. Information from the parent organisation

3. Information at the national and regional level. ${ }^{53}$

The differences between a management information system and a decision support system lie not only their features, but also in their users. Management information systems tend to be used by lower and middle management because of their ability to assist in making structured decisions. In contrast, decision support systems tend to be more useful to top management because they can help with decisions on unstructured issues. Where they exist, decision support systems appear to be mainly used at the strategic management level. ${ }^{54}$

\section{Library automation}

Early opinions of the potential uses of computers in libraries varied. One university librarian observed that:

'... computers can be used in library operations. It does not prove that they should.' 55

Despite such ambiguous attitudes, decreasing library budgets have been a significant factor in persuading the management of many academic libraries of the benefits of computerising library activities.

'Many librarians have found over the last ten years or so that they have been unable to recruit more staff but their work loads have increased, perhaps by an increase in student number in an academic library, or by acquiring more books, or by the library and its services being used more. In order to cope with such situation many librarians have decided to use computer systems.' 56

Librarians have been very careful in selecting, acquiring and installing an automated system. Moreover the setting up of library cooperatives, such as BLCMP, SWALCAP and SCOLCAP, contributed greatly to the development of library automation through a sharing of expertise and requirements. The limited abilities of the early automated systems have in many ways been overcome in the integrated, turnkey systems developed by the cooperatives and the commercial system vendors.

The decision to introduce library automation was usually based on a re-appraisal of the objectives of the library, for example:

- to make the most of effective use of existing library manpower and resources for the benefit of library users

- to allow for integration of all aspects of information management relevant to the library's work now and in the future 
- to create a user-friendly environment in which the information handling and information processing needs of both library staff and library users, as an integral part of the learning process, are addressed

- to facilitate vertical integration of the library's current microcomputer-based systems. ${ }^{57}$

In the early phase of automation, it was common that many academic libraries used their parent institution's computer facilities. Few had their own because of the then relatively high cost. Since computer prices have fallen, many academic libraries have acquired their own computers for library operations. In the university context:

'libraries became less dependent upon their parent institutions for central computing facilities, and most now have their own hardware.' ${ }^{58}$

Current technology may integrate the system in the library with that in its parent institutions, or stand alone. Although IT systems may be stand-alone:

'The complex task of senior management in any field is not necessarily best served by the use of individual software packages. The growth of networks, the provision of information by MIS; and the ability of decision support systems to model decisions and analyse possible effects - these are likely in the long term to prove more useful tools for senior managers. The next few years will probably see a gradual increase in utilisation of these integrated management support systems in academic libraries.' 59

The advantages of integration are, for senior library managers, enhanced by micro-computers and intelligent terminals:

'The importance of these devices for the management information systems lies in their ability to acquire data from the organisation's main computer and to process it, using their own software, within the device itself. Not only is there a saving in processing load on the main machine, but the manager can be assured of a very fast response and of confidentiality and can have the software tailored to his own specifications without affecting other users. In addition many intelligent terminals provide flexible control over the information which is displayed, so that not only text but graphics can be produced and manipulated. This can be a major advantage where complex statistical data has to be presented.' 60

\section{Current use of management information in academic libraries}

A small survey of current use of management information systems in British academic libraries was undertaken by visiting eight libraries in late 1991. The libraries visited consist of four university libraries, three polytechnics in England and one Central Institution in Scotland. Of the four university libraries, three were in Scotland and one was in England.

There were two principal reasons for choosing these libraries. First, some of their chief librarians had been identified as notable contributors to the literature on academic library management. Second, all the libraries employed automated library systems. It was expected that the librarians would have been changing the way they manage to enable them to cope with financial pressures. In particular, it was expected that they would be concerned to know what is happening in their libraries in order to spend their budgets in the most efficient manner to achieve their objectives. 
A questionnaire was prepared in advance, as the basis for structured interviews with the chief librarians, and was sent to them a few days before the visits so that they could consider their responses. In the event, five chief librarians, two deputy librarians, and three senior librarians were interviewed. The interviews ranged from one hour to four hours. In addition, library annual reports and other printed information related to the purpose of the survey were obtained and scrutinised. The following description of the general circumstances and management information systems in those libraries is, therefore, based on information gathered from interviews, printed information, and demonstration of their automated systems.

The eight libraries visited were examined in terms of their planning systems, financial management, buildings utilisation, the state of automation, participation in cooperative activities, acquisitions and collection management, staffing, evaluation processes, and the implications for Management Information Systems.

\section{Library planning and objectives}

All the libraries had produced a statement of their mission, medium-term plans, and specific objectives or targets. One library operated on a planning cycle of three years, and the others on five years. Thus, this was a common management activity, with the potential for providing guidelines for resources allocation, and a basis for management information systems.

\section{b. Finance}

As the result of financial pressures, the libraries visited had mostly changed their approach to financial management. Cost centres and budget centres are more commonly used than in earlier years since they provide a means of allocating finance in a way more relevant to the evaluation of the library plans. The libraries which are using budget centres or cost centres have been employing a scientific/quantitative approach to resource allocation. Only three libraries still use their traditional budgetary structures and allocate resources on a historical basis. Despite differences in the schemes used for resources allocation, all the libraries had produced and continue to produce some kind of statistical data. The reasons for producing statistical data vary: in general, the data is intended to contribute information to the institution's finance system, and annual reports, or to meet requests from SCONUL or, formerly, COPOL. A requirement to produce general statistical data about the library for managerial use by its parent institution is not common; it was found in only one library.

\section{c. Buildings utilisation}

The librarians were, of course, aware of the self renewing concept promoted in the Atkinson report in an attempt by government to restrict the demand for new university library buildings to accommodate ceaselessly growing collections. ${ }^{61}$ Attempts to apply the concept had been tried but then put aside. The reasons were clear. There have been important changes in the institutions, as the government has permitted and encouraged growth in student numbers. The introduction of new courses and an increased number of students represent different and urgent problems for academic library services, and have rendered the self renewing concept redundant - at least for the moment.

Consequently, libraries had less need of information to assist decision making on what to do with their collection in order to save space. They have more need of 
information to assess the adequacy of their collections, study places, and usable space to meet the growing demands on them. Nonetheless, in only one polytechnic and one university did the librarians have information on shelf space available for new materials.

\section{d. The state of automation}

Automated systems were mostly established in the early 1980s. Now, all librarians were concerned with the cost of maintenance, but recognised that it is offset by improved productivity in the libraries' operations. Microcomputers had been gradually introduced, but two chief librarians did not yet have them in their own offices, allegedly because they were considered too expensive.

Nonetheless, in one Scottish university it was planned to introduce the use of microcomputers and spreadsheets for financial data systems. This development was being promoted by the chief librarian even though he did not have a microcomputer in his own office to use that spreadsheet. There were some indications that the librarians were willing to introduce automated management information systems. Progress had been slow, however, and finance was a major barrier.

\section{e. Participation in cooperative activities}

The libraries were generally members of some cooperative scheme, particularly SCONUL and COPOL, both of which compile and disseminate comparative information on library performance. Thus, to some extent, these organisations are already contributing to the development of management information systems.

\section{f. Acquisitions and collection management}

All the libraries were suffering from reduced purchasing power. They could acquire fewer books and serials despite increases in their budgets. Overspending on periodical subscriptions was also a problem in some libraries, and had become the main issue, generally, in senior staff meetings.

Most libraries had information on numbers of books borrowed, but similar data on the use of periodicals is not commonly collected, so although the librarians are aware of the reduced power of periodicals budgets, decisions on which periodicals subscriptions to retain could not easily be made. It was believed to be a very critical area that needed to be managed more carefully, and it was hoped that automated management information systems could be established to do this.

\section{g. Reader services}

Two points were made which relate to the need for management information about reader services. First, there is a need to monitor utilisation and opening hours. Clear information on the number of users who come to the libraries in the evening, for example, must be compared against the cost of staff. Second, online services had already been introduced in all academic libraries, since they can be expensive services, charges had been introduced in most libraries. CDROMs are increasingly widely available free of charge; as a consequence, the number of inter-library loans has increased. Information is needed by library management on all these areas to enable the most cost-efficient and sustainable solution to be implemented. 


\section{h. Staffing}

All but one of the libraries had increased their expenditure on library staff as a proportion of the total budget. They all currently faced the problem of managing a workload arising from increased numbers of students with a reduced staff. There appeared to be a readiness among library staff to establish automated management information systems to monitor the workload and to simplify some reporting tasks.

\section{i. Evaluation processes}

Formal and comprehensive evaluation processes might be supposed to be in place in all the libraries since all the librarians were aware of the need for quantitative and qualitative data about their libraries, but there was only one university library which claimed that it had a formal and comprehensive system for library evaluation. Most libraries claimed to have an informal system and to be trying to introduce formal ones.

They were aware of the existence of performance measures and performance indicators which would help them to evaluate their libraries, but only two libraries had experimented with performance measurement, and only one had fully implemented a formal system through the development of an experimental decision support system.

Two of the eight libraries had no immediate plans to introduce the use of performance indicators. Neither the chief librarians nor senior librarians were promoting their introduction. The other five libraries were moving to introduce the use of performance indicators. This was being promoted by chief librarians because of a perceived need for quantitative and qualitative data. There appeared to be little suggestion that it was being done simply because it was fashionable.

Three of the five libraries are using mostly paper-based management information systems. Two others are using microcomputer networks. Of the rest, two libraries had discontinued collecting internal information, and one has never collected information for use as performance indicators.

In terms of the use of performance indicators in decision making, the one library which uses performance indicators stated that they had a considerable impact on decision making; most of the others suggested that performance indicators had little impact on decision making.

Despite the lack of formal performance measurement in some libraries, all had a financial data system. Current reports from the financial data system are said to be adequate for decision making, and for the libraries' annual, reports, as well as meeting the needs of the institutions' own finance departments.

\section{j. Use of external information for library planning}

The library plans and objectives in the libraries visited showed that they were aware of current external trends. Their parent institutions' plans were the principal source of information about future developments. In addition, they took account of information from outside institutions such as government departments and, in particular, the higher education funding councils. Other information sources which were mentioned consisted of other libraries' annual 
reports. Information UK 2000,62 users' comments on the library services, publishing trends, etc. To obtain comparative data about their libraries' performance, they made heavy use of SCONUL and COPOL data.

Most external information is acquired in printed form. Some information sources are kept in the chief librarians' offices, others in the senior librarians': no one had a comprehensive collection of the external information in their own offices. Two libraries had recorded some external information, e.g. information on price inflation, in their microcomputers.

Although there are serious problems in data processing, the range of external information held shows that there was the potential to establish a comprehensive management information system. The external information would, however, have to be tailored with other information in order to be used in decision making.

\section{The availability and use of management information systems}

Three libraries claimed that they had management information systems in their institutions and libraries. One library had a partial system in both the institution and the library, and was trying to develop a comprehensive one in library. One had a partial system in the library, and was attempting to have a comprehensive one, even though there was no management information system in its institution.

Of those who did not have management information systems in their libraries, three librarians offered the explanation that this was because there was no management information system in the institution. One commented that its attention was concentrated on selecting and introducing a reliable turnkey automated system. All librarians mentioned that user friendliness and inexpensiveness are priorities in establishing their management information systems.

Apart from the library which has decision support systems, current automated library systems are not fully used for formal management information systems, even though these could perhaps provide enhanced information for performance measurement and could contribute to the establishment of a more comprehensive evaluation of the achievement of the libraries' objectives. In terms of the ability of their automated system to support a management information system, all the libraries stated that existing systems were generally helpful in data processing. However, they produced output data which is crude and which has to be further manipulated before it can be interpreted. Seven of the libraries' computer systems produce quite complete operational data such as statistics of cataloguing, circulation, etc., but no system provides statistical data on reference services. One university library struggled to collect even crude data since its turnkey system has limited capabilities. It produces only data on circulation and stocks, and lacks compatibility with any other automated system in the library or the institution. Therefore, in order to have data in usable form and when needed, all libraries must at present manipulate them. Two libraries, however, had microcomputers which had no downloading facilities: they first had to print out the data from larger computers and manipulate it manually before inputting it into a microcomputer to be used with other information. Others did have microcomputers with downloading facilities, and could use them to process 
the crude data into usable outputs. All the libraries thus employ workable methods of producing management information, but they lack immediacy, and are expensive to operate.

The forms of output vary. Those libraries which had formal management information systems had facilities to examine them online, but mostly data is presented in hard copy. Libraries which had informal and/or partial management information systems tended to rely on on-demand reporting.

Although most libraries stated that the outputs are easily read, analysing the outputs of the system depends mostly on the abilities of the users to interpret them. Outputs provide information for junior, senior and chief librarians.

Graphical presentations were available to make numerical data understandable in a very short time. Apart from the information provided for junior management, the outputs of management information systems are generally discussed in senior staff meetings on a weekly or monthly basis.

With regard to decision making in the areas of library planning and evaluation, in particular budgeting and resources allocation, two chief librarians stated that management information systems had made a great impact in the sense that all decisions were made based on the information from their systems. This is due to the comprehensiveness of the information made available. Their systems can provide only crude data, but it can be interpreted easily so that it assists in answering very specific questions. Microcomputers can also examine a 'what ... if' scenario by modelling different situations.

\section{Management information systems and the staff structure}

Seven of the eight libraries claimed that they already had a 'flat' management structure, and are trying to avoid a more hierarchical staff structure. However, the current structure was said to be uninfluenced by the existence (or absence) of a management information system. Rather, it was due to the need to establish a structure which was customer oriented, which provided a clear definition of the responsibilities of staff, and which facilitated the flow of instructions or information. One university librarian also stated that the hierarchy that had been retained was intended to facilitate staff promotion.

\section{Opinions on decision support systems}

Libraries which had formal management information systems found that the management information produced by their system needed to be carefully interpreted; moreover, the management information systems were not proactive. Therefore, their aim was the introduction of decision support systems in the near future. Those libraries which had only informal management information systems saw that they had the choice of establishing either a formal management information system or a decision support system. They indicated that they were more likely to favour decision support systems.

All of the librarians interviewed were aware of the nature and potential of decision support systems, and saw them as particularly helpful in utilising performance indicators and developing quality assurance processes in the library. One library was already experimenting with a decision support system and 
performance indicators, and three were aiming to have one. One librarian, however, had no intention to have a decision support system, as he felt that it could assume too much control, as well as being very difficult to establish. However, all were agreed that decision support systems are more reliable than management information systems.

Nevertheless, in terms of infrastructure for decision support systems, little progress was evident. Only one library had a microcomputer based network, and one other was preparing to have one.

\section{Use of automated systems for management information systems and effects on decision making}

All of the libraries visited already employed automated systems. However, formal and relatively fully automated management information systems existed in only two of the eight libraries visited. They had been established because of the existence of management information systems in the institutions as a whole. In the other libraries, the use of cost centres for resources allocation caused the libraries to have some formal management information. Libraries generally are not fully utilising the capability of their automated systems since some external information remains in printed form, and manual data processing is still a significant element in their analysis of the data available.

Those librarians who had 'informal' or 'partial' management information systems had concluded that a management information system would be not helpful for decision making in budgeting and resource allocation, but they still faced a requirement to produce reports for their institutions, particularly for their finance departments, which incorporate management data. They also produce summary information for various purposes, profiling their parent institution, finance, staff, users, facilities and equipment, programmes and functions. Those libraries which had management information systems possessed information which was deeper in substance and more readily available, so it was easier for them to make appropriate decisions.

\section{Barriers to the development of management information systems}

There were several reasons why many of the libraries visited lacked management information systems. The criteria of an ideal management information system are that:

- they must be inexpensive to operate

- they must not interfere with existing services

- they must provide reproducible results. ${ }^{63}$

The fact that some libraries claimed to have only 'informal' or 'partial' management information systems or to have no management information systems does not mean that they had no collection of external and internal data. They do collect and use information for establishing library objectives and priorities or for resources allocation, but they have not formalised their management information systems, typically because their institutions had not required them to do so. 
Other factors which had inhibited development are mainly technical and concern the libraries' infrastructures. The limited capabilities of their computers had resulted in misinterpretation of the output data, and faulty analysis by senior library staff. This was compounded by a lack of staff training in analysing data. The emphasis on purchasing microcomputers for library users was also a drain on scarce resources which might otherwise have been used to set up automated management information systems. Incompatibility of computer systems also caused problems; for example, in the workload involved in inputting common data such as the identity of students as compared with simply capturing it from a central database. Although they had enough potential to support formal management information systems, less use is made of existing automated library systems than might be possible given some development of their software. Even in the two libraries which had management information systems, there is one evident weakness; neither library has identified a comprehensive range of performance measures.

\section{Summary and conclusions}

The contemporary approach casts academic librarians as managers within the higher education system. Planning and controlling development is clearly an important aspect of that role. Academic libraries' objectives have become clearer than in the past, but British academic libraries' attempts to achieve those objectives have been threatened by government financial policies which, in effect, require academic libraries to provide more and better services with less money. Consequently, every aspect of academic libraries' operations has to be reviewed so that they can be managed more effectively and efficiently. It is not easy to achieve this because academic libraries are complex organisations.

What academic librarians need, now much more than ever before, is the information which will allow them to plan properly, to know whether or not the library service is meeting the needs of the academic community and to be able to demonstrate that to the internal and external authorities responsible for funding. Performance measures are also necessary in order to reveal libraries' strengths and weaknesses when compared with internal and external targets, norms and averages.

From the survey, it is clear that most library managers are very concerned with the need for management information about their libraries. Libraries have generally established objectives and forward plans; there are still differences in how they allocate resources to fulfil those plans, and clear divergences of opinion on what information is required for library planning and resources allocation. Changing circumstances may call for any aspect of libraries' resources and services to be reviewed, or for them to be considered from a different perspective, often pro-actively or at fairly short notice, and the advantages of a comprehensive management information system should be self-evident. Similarly, although at present there is much data collection, formal evaluation processes are not common. Performance measures which can compare internal and external information have not been widely utilised and have made little impact in decision making, perhaps because there is no agreement on what constitutes appropriate measures of achievement. 
Structured management information systems could help library managers in collecting and processing data into a useful form to assist in decision making. Most libraries appear to collect the same data, but only two of the eight selected libraries had established comprehensive management information systems for their librarians' purposes, in particular to support the planning process. Although they had not fully automated data processing and reporting, and the information from their systems needs to be carefully interpreted, these librarians are making decisions based on outputs from their management information systems.

The introduction of computers into academic libraries was largely a response to the problem of dealing with increased workloads with fewer staff, and they are now able easily to handle most of the routine and repetitive work of the library staff. In addition, they have the capability to enhance the provision of management information, since automated data processing is able to present reports more accurately and much faster than manual systems. A limited range of data processing for management information is currently supported by the computer systems, including microcomputers, available in academic libraries, but there are still significant weaknesses in library automation systems in respect of the production of management information. For example, much remains to be done in monitoring high cost areas such as serials management and staff deployment in reader services. Consequently, apart from the one library visited which has a decision support system, current library automation systems are not fully used for formal management information systems. It has to be said that most librarians still consider the continuous costs of automation as a worrying expense, and that the development of management information systems is not seen as a high priority compared with the introduction or upgrading of new automation systems for handling routine operations.

Nonetheless, most librarians claim that they would now like to install decision support systems, even though they see the expense as a problem. The likelihood of increasing requirements for information to be provided at institutional level to meet government demands that institutions should be accountable may change priorities and foster developments. While waiting for these developments, and for this new technology to be proved, attempts must be made to find out whether there will be support for the establishment of management information systems or decision support systems, and in particular, whether there will be support from the parent institutions and the library staff. The introduction of automated management information systems seems unlikely to pose a threat to staff in academic libraries, as most already have a 'flat' management structure, but a priority must be training programmes on the use of information in management. Support from parent institutions is also essential since the technology required for decision support systems could be expensive, particularly if they are seen as separate from the replacement of the libraries' existing automated systems.

It will, therefore, be important to convince the vendors who produce turnkey library automation systems to develop new systems which provide more of the management information that meets widely recognised needs in terms of both contents and format. There is a bewildering array of information available from a variety of external and internal sources, and, in addition to the costs of collection and collation, it generally needs tailoring to meet libraries' needs for comparable data. Cooperative groups such as SCONUL have a role to play here 
in developing guidelines on the information needed, and the format(s) in which it should be presented for comparative purposes. Present outputs from library automation systems are crude, but the work currently being undertaken to develop both performance measures which have wide applicability and credibility, ${ }^{64,65}$ and more effective management information modules as part of library automation systems ${ }^{66}$ should eventually resolve that problem.

\section{References}

1. RODGER, E.M. Evaluation of library and information services in times of economic restraint: the UK university view. Outlook on Research Libraries, 10 (4), 1988, 9-13. 2. MACKENZIE, A.G. Academic libraries in contraction: facts, theories and fancies. Aslib Proceedings, 38 (9), September 1986, 317-325.

3. SPARROW, E. Management information in the British Library Humanities and Social Sciences Division. Journal of Librarianship, 20 (2), April 1988,94-107.

4. MCCLURE, C.R. The planning process: strategies for action. College and Research Libraries, 39 (6), November 1978, 456-466.

5. SPARROW, E. op. cit.

6. PAYNE, P. and WILLERS, J.M. Using management information in a polytechnic library. J ournal of Librarianship, 21 (1), January 1989, 19-35.

7. REVILL, D.H. Cost centres and academic libraries. British Journal of Academic Librarianship, 4 (1), 1989, 27-47.

8. DEPARTMENT OF EDUCATION AND SCIENCE. Performance indicators in higher education: a report by HMI. London: Department of Education and Science, 1990.

9. VON COTTA-SCHONBERG, M. Automation and academic library structure. Libri, 39

(D. March 1989,47-63.

10. STUEART, R.D. and EASTLICK, J.T. Library management. Colorado: Libraries Unlimited, 1981,56-77.

11. HUNT, C.J. Staff structures. In LINE, M.B. ed. Academic library management. London: The Library Association, 1992, 166-172.

12. ibid.

13. REVILL, D.H. op. cil.

14. LINE, M.B. Library management styles and structures: a need to rethink? J ournal of Librarianship and Information Science, 23 (2), June 1991, 97-103.

15. CARGILL, J. Creativity and innovation in public service. Journal of Library

Administration, 10 (2/3), 1989, 49-55.

16. HEIM, K.M. Organisational considerations relating to the implementation and use of management information systems. In: LANCASTER, F.W. Library automation as a source of management information. Urbana-Champaign: University of Illinois, 1982, 59-70.

17. ibid.

18. BROPHY, P. Management information: the academic library. In Harris, C. ed.

Management Information Systems in libraries. London: Taylor Graham, 1987, 29-39.

19. RADFORD, K.J. Modem managerial decision making. Virginia: Prentice-Hall, 1981, 1.

20. AHITUVE, N. and NEUMANN, S. Principles of information systems for management.

3rd ed. Dubuque: Wm.C. Brown Publishers, 1990, 36-37.

21. HOMER, G. Management information systems can help senior library managers.

Canadian Library Journal, 43 (3), June 1986, 141-145.

22. BRINDLEY, L. Monitoring and management information. In LINE, M.B. ed. Academic library management. London: Library Association, 1990, 206-215.

23. ibid.

24. SPARROW, E. op. cit

25. MACKENZIE, A.G. Performance Measurement. In Line, M.B. ed. Academic library management. London: Library Association, 1990, 196-205.

26. BLOOR, I.G. Performance indicators and decision support systems for libraries: a practical application of 'keys to success.' London: British Library, 1991, 6-7 
27. MACDOUGALL, A. Performance assessment: today's confusion, tomorrow's solution? In: Proceedings of the $51^{\text {st }}$ IFLA Conference, Moscow, August 1991, 33-38.

28. VAN HOUSE, N.A., el. at. Measuring academic library performance: a practical approach. Chicago: American Library Association, 1990, 3.

29. BLOOR, I.G. op. cit. 5.

30. REDFERN, M. Giving an account: performance indicators for libraries. Library Review, 39 (5), 1989,7-9.

31. WINKWORTH, L. Performance indicators for polytechnic libraries. Library Review, 39(5). 1990,23-41.

32. BLOOR, I.G. op. cit. 11.

33. HEIM, K.M. op. cil.

34. LINES, L. Performance measurement in academic libraries: a university perspective. British Journal of Academic Librarianship, 4 (2), 1989, 111-119.

35. RIGGS, D.E. Strategic planning for library management. Phoenix: Oryx Press. 1984, 78.

36. CULLEN, R. A model of a management information system for library and information service managers. International Journal of Information and Library Research, 2 (1), 1990, 23-34.

37. BRYSON, J. Effective library and information centre management. 1990. Aldershot: Gower,211.

38. MILLERCHIEF, J.J.G. Personal management skills. London: The Library Association, $1990,117$.

39. HICKS, J.O. Management information systems: a user perspective. New York: West Publishing, 1984.

40. AHITUVE, N. and NEUMANN, S. op. cil. 133.

41. HOMER, G. op. cil.

42. TAGUE, J. Computer potential for management information. Canadian Library Journal, 36 (5), October 1979, 268-270.

43- BROPHY, P. Management information and decision support systems in libraries. Aldershot: Gower, 1986, 119-129.

44. ibid.

45. ibid., 42-44.

46. ibid., 42-44.

47. HAWKS, C.P. Management information gleaned from automated library systems. Information Technology and Libraries, 7 (2), J une 1988, 131-138.

48. BRAISBY, P.S. el. at. Development of management information systems for academic libraries: concepts, principles and outline research programme. London: British Library, 1987, 17.

49. BEE, R. and BEE, F. Management information systems. London: Institute of Personnel Management, 1990, 1-6.

50. LUCEY, T. Management information systems. 5th ed. London: DP Publication, 1989, 16.

51. LIBRARY ASSOCIATION, COLLEGES OF FURTHER AND HIGHER EDUCATION GROUP. Guidelines for college and polytechnic libraries. 4th ed. London: The Library Association, 1990, 3.

52. ADAMS, R. et. al. Decision support systems in academic libraries. London: British Library, 1991, 8-9.

53. ibid.

54. BRYSON, J. op. cil.

55. HIGHAM, N. The library in the university: observations on a service. London: Andre Deutsch, 1980, 152.

56. TEDD, L. An introduction to computer-based library systems. Chichester: John Wiley, 1984, 7.

57. DUNSIRE, G. and FINDER, C. Dynix, automation and development at Napier

Polytechnic. Program, 25 (2), April 1991, 91-103. 
58. RODGER, E.M. Progress in documentation - British university libraries 1977-1987: some observations on the challenges of declining resources. Journal of Documentation, 44 (4), December 1988, 346-378.

59. HAYTER, M. and HEERY, M. Use of IT by senior managers in UK academic libraries. Aslib Proceedings, 41 (6), June 1989, 203-211.

60. ibid.

61. Capital provision for university libraries: report of a Working Party [of the University Grants Committee under the Chairmanship of Professor Richard Atkinson]. London:

H.M.S.O., 1976 ('The Atkinson Report').

62. MARTYN, J. Information UK 2000. London: Bowker Saur, 1990.

63. RUNYON, R.S. Toward the development of a library management information system. College and Research Libraries, 42 (6), November 1981, 539-548.

64. J oint Funding Councils' Ad Hoc Group on Performance Indicators. The effective academic library: a framework for evaluating the performance of UK academic libraries. 1995. Bristol: HEFCE Publications.

65. Mention should also be made of the work being undertaken on an international level by the International Federation of Library Association and Institution's Section on University Libraries to develop appropriate performance measures.

66. e.g. the DECIMAL (DECl sion MAking in Libraries) project, funded by the European Commission as part of its Telematics Programme Libraries Workplan, which is coordinated by the Department of Library and Information Studies at Manchester Metropolitan University and involves a number of collaborating institutions and Inheritance Systems Ltd. 